\title{
Fish consumption is inversely associated with type 2 diabetes in Manitoba First Nations communities
}

\author{
Lesya Marushka $a^{a}$, Malek Batal ${ }^{\mathrm{b}}$, Donald Sharp ${ }^{\mathrm{c}}$, Harold Schwartz ${ }^{\mathrm{d}}$, Amy Ing $^{\mathrm{b}}$, Karen Fediuk ${ }^{\mathrm{e}}$, \\ Andrew Black ${ }^{c}$, Constantine Tikhonov ${ }^{\mathrm{d}}$, and Hing Man Chan ${ }^{\mathrm{a} *}$ \\ ${ }^{a}$ Biology Department, University of Ottawa, 180 Gendron Hall, 30 Marie Curie, Ottawa, ON K1N 6N5, \\ Canada; ' Nutrition Department, Faculty of Medicine, Université de Montréal, Pavillon Liliane de Stewart, \\ 2405 Côte-Sainte-Catherine Street, Montreal, QC H3T 1A8, Canada; 'Assembly of First Nations,

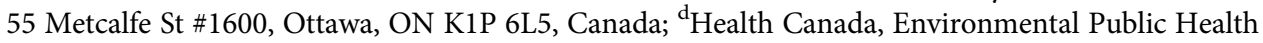 \\ Division, First Nations and Inuit Health Branch (FNIHB), Room 2000A Jeanne Mance Bldg. AL 1920A, \\ Tunney's Pasture, Ottawa, ON K1A 0K9, Canada; ${ }^{e}$ Dietitian and Nutrition Researcher, Ladysmith, BC, \\ Canada \\ *laurie.chan@uottawa.ca
}

\section{Abstract}

Consumption of fish and n-3 fatty acids (n-3 FAs) has been postulated to prevent type 2 diabetes (T2D).

Objective: To explore the association between self-reported T2D and fish consumption, dietary n-3 FAs, and persistent organic pollutants (POP) intake in a regionally representative sample of First Nations (FNs) in Manitoba.

Design: Data from the cross-sectional First Nations Food, Nutrition and Environment Study (FNFNES) collected from 706 members of 8 Manitoba FNs in 2010 were used. Household interviews were used to collect social and lifestyle data. The consumption of fish was estimated using a traditional food frequency questionnaire. Fish samples were analyzed for the presence of POP. Multiple logistic regression models adjusted for potential risk factors for T2D were developed.

Citation: Marushka L, Batal M, Sharp D, Schwartz H, Ing A, Fediuk K, Black A, Tikhonov C, and Chan HM. 2017. Fish consumption is inversely associated with type 2 diabetes in Manitoba First Nations communities. FACETS 2: 795-818. doi: 10.1 | 39/facets-2017-0023

Editor: Hugh W. Davies

Received: March 3, 2017

Accepted: August 3, 2017

Published: October 19, 2017

Copyright: (C) 2017 Marushka et al. This work is licensed under a Creative Commons Attribution 4.0 International License (CC BY 4.0), which permits unrestricted use, distribution, and reproduction in any medium, provided the original author(s) and source are credited.

Published by: Canadian Science Publishing
Results: A negative, dose-response relationship was found between fish intake and self-reported T2D. Fish consumptions of 2-3 portions per month and $\geq 1$ /week were inversely associated with T2D with odds ratio (OR) values of 0.51 (95\% CI: $0.28-0.91$ ) and 0.40 (95\% CI: 0.19-0.82), respectively, compared with no fish intake. Similarly, intake of n-3 FAs was negatively associated with T2D $(\mathrm{OR}=0.48$ (95\% CI: 0.30-0.77). Dietary POP intake was not associated with T2D.

Conclusion: These findings suggest that the consumption of traditionally harvested fish may have a beneficial effect on T2D in Manitoba FNs.

Key words: First Nations, fish consumption, Manitoba, long chain n-3 fatty acids, persistent organic pollutants, type 2 diabetes

\section{Introduction}

The prevalence of type 2 diabetes (T2D) has been steadily increasing worldwide, substantially contributing to health care costs (Guariguata et al. 2014). In Canada, T2D is one of the most common chronic diseases. According to recent statistics, the prevalence of T2D in Canada has more than doubled between 2000 and 2010 (increasing from 1.2 to 2.4 million affected), and this trend is 
projected to continue (Pelletier et al. 2012; Canadian Diabetes Association 2015). The prevalence of T2D was $8.9 \%$ in 2015 and is estimated to reach $11.4 \%$ by 2025 (Pelletier et al. 2012; Canadian Diabetes Association 2015). The Canadian First Nations (FNs) population is experiencing rates of T2D of epidemic proportions. The prevalence of T2D in FNs communities is 3-5 times higher than that in the general Canadian population (Young et al. 2000; Dannenbaum et al. 2008; Pelletier et al. 2012). In addition, an earlier age of diabetes onset, a greater severity of the disease, and higher rates of complications of T2D are observed in on-reserve FNs compared with non-Indigenous populations (First Nations Information Governance Centre 2012). FNs women experience higher rates of T2D than FNs men, in contrast to the pattern observed in the general Canadian population (Pelletier et al. 2012). This is thought to be because FNs women have higher rates of obesity than FNs men, and experience high rates of gestational diabetes, which increases the risk of T2D later in life (Millar and Young 2003).

The rapid increase in the prevalence of T2D in FNs over the last four to five decades has been influenced by a variety of risk factors including genetic, sociocultural, environmental, and lifestyle factors (Young et al. 2000). Historically, the diet of FNs was based on traditional foods harvested from the local natural environment. This traditional food consisted of wild meat, fish and bird species, plants, and berries acquired by traditional hunting, fishing, and gathering, contributing to the intake of essential nutrients as well as physical activity and the well-being of FNs (Kuhnlein and Receveur 2007; Jamieson et al. 2012). FNs have been undergoing rapid lifestyle and dietary transitions, moving from a traditional high-nutrient diet toward consuming store-bought energy-dense food that is associated with increased rates of obesity and T2D (Kuhnlein et al. 2004).

T2D is associated with numerous complications including retinopathy, neuropathy, kidney disease, and cardiovascular disease, which may lead to disability and mortality (Naqshbandi et al. 2008). A number of modifiable risk factors for T2D are well established including overweight and obesity, poor diet, sedentary lifestyle, and smoking. Among dietary factors, fish consumption and long-chain omega-3 fatty acids (n-3 FAs) eicosapentaenoic acid (EPA) and docosahexaenoic acid (DHA) have been postulated to prevent T2D. n-3 FAs intake showed a favorable effect on insulin sensitivity in animal models (Fedor and Kelley 2009). Data from an ecological study demonstrated that the prevalence of T2D was low in regions where fish consumption was high (Nkondjock and Receveur 2003). In addition, the beneficial effects of fish consumption and n-3 FAs intake on T2D are supported by studies conducted in northern Indigenous populations. Specifically, the Inuit population has lower rates of metabolic and cardiovascular diseases (Deering et al. 2009) than the general populations of Canadians and FNs. This is attributed to the beneficial effect of the consumption of traditional food rich in n-3 FAs (Dewailly et al. 2001), which resulted in higher concentrations of EPA and DHA in plasma and serum phospholipids (Proust et al. 2014). The results of epidemiological studies in general populations have been inconsistent regarding the association between fish consumption and n-3 FAs and T2D prevalence. Several prospective cohort studies reported protective effects of fish consumption and n-3 FAs intake on the risk of T2D (Patel et al. 2009; Nanri et al. 2011; Villegas et al. 2011), whereas some studies suggest positive (Kaushik et al. 2009; Djoussé et al. 2011) or no associations (van Woudenbergh et al. 2009). Meta-analyses reported geographical differences in the associations between fish consumption, n-3 FAs, and the development of T2D; a protective association was observed in the populations of Asian countries, and a positive association was observed in the American population (Muley et al. 2014).

Despite its beneficial attributes, fish can be a route of exposure to environmental contaminants such as persistent organic pollutants (POP), including polychlorinated biphenyls (PCB) and dichlorodiphenyldichloroethylene (DDE). POP are lipophilic compounds that persist in the environment and, therefore, bioaccumulate and biomagnify within living organisms such as fish and mammals 
(Sobek et al. 2010; Seabert et al. 2014). Several epidemiological studies have reported a positive association between diabetes and POP including PCB, DDE, and dioxins and dioxin-like chemicals (Lee et al. 2006; Codru et al. 2007; Philibert et al. 2009). These findings are supported by an experimental study that showed a link between exposure to POP and insulin resistance, visceral obesity, and glucose intolerance (Ibrahim et al. 2011). High concentrations of POP in blood have been reported for northern Indigenous populations (Donaldson et al. 2010). Traditional food, in particular fish, is considered the major source of exposure to POP (Seabert et al. 2014).

Given the increasing prevalence of T2D and potential exposure to contaminants through fish consumption in FNs, we aim to describe fish consumption patterns among First Nation adults in four Manitoba ecozones; to estimate n-3 FAs, PCB, and DDE intake from fish; and to explore the association between fish consumption and dietary DDE, PCB, and n-3 FAs intake and self-reported T2D in a representative sample of FNs adults living on reserves in Manitoba.

\section{Methodology}

\section{Study population}

We analyzed data from the First Nations Food, Nutrition and Environment Study (FNFNES) (fnfnes.ca). FNFNES is a cross-sectional study designed to assess total diets, food-related exposure to contaminants, and food security status of FNs people living on reserves south of the 60th parallel across Canada (Chan et al. 2012). FNFNES collected data from approximately 100 FNs communities across Canada. FNs communities were randomly sampled using a combined ecozone/cultural area framework. An ecozone is a large geographical region identified based on the distribution patterns of plants, animals, geographical characteristics, and climate (ecozones.ca). "Culture areas" is a concept for identifying geographic areas within which Indigenous communities share a greater number of traits/cultural affinities than those outside the area (Chan et al. 2012). The sampling was done in three stages: primary sampling was performed with the random selection of communities within each ecozone; secondary sampling was conducted with the random sampling of 125 households within each selected community; and tertiary sampling wherein one adult in each household who was selfidentified as being a FNs person aged 19 and older living on a reserve was asked to participate in the study. Sample weights were calculated to permit inferences from persons included in the sample about the total population from which they were drawn, and to obtain data that reflect estimates of the population totals. Using sample weight minimizes biases arising from differences between participating and non-participating persons (Maletta and Aires 2007). The design weight was adjusted based on the assumption that the information obtained from responding communities is representative of both responding and non-responding communities. Assuming that non-response is not related to the topic of the study (missing at random), a non-response adjustment factor was calculated within each stratum. The Bootstrap method was adopted for assessing the sampling error of the estimates produced for this study (Chan et al. 2012). The current study included data collected in 2010 from nine Manitoba FNs communities across four ecozones: (1) Prairies/Plains, Prairies/Subarctic, (2) Boreal Plains, Plains/Subarctic, (3) Boreal Shield/Subarctic, and (4) Taiga Shield/Subarctic (Fig. 1). The overall participation rate was $82 \%$. In total, 706 participants (477 women and 229 men) aged 19 years and over were interviewed for this study.

\section{Ethics}

Individual participation in the project was voluntary and based on informed written consent after an oral and written explanation of each project component. This survey was conducted following the "Tri-Council Policy Statement: Ethical Conduct for Research Involving Humans" and in particular Chapter 9, pertaining to research involving the FNs, Inuit, and Métis Peoples of Canada. The study 


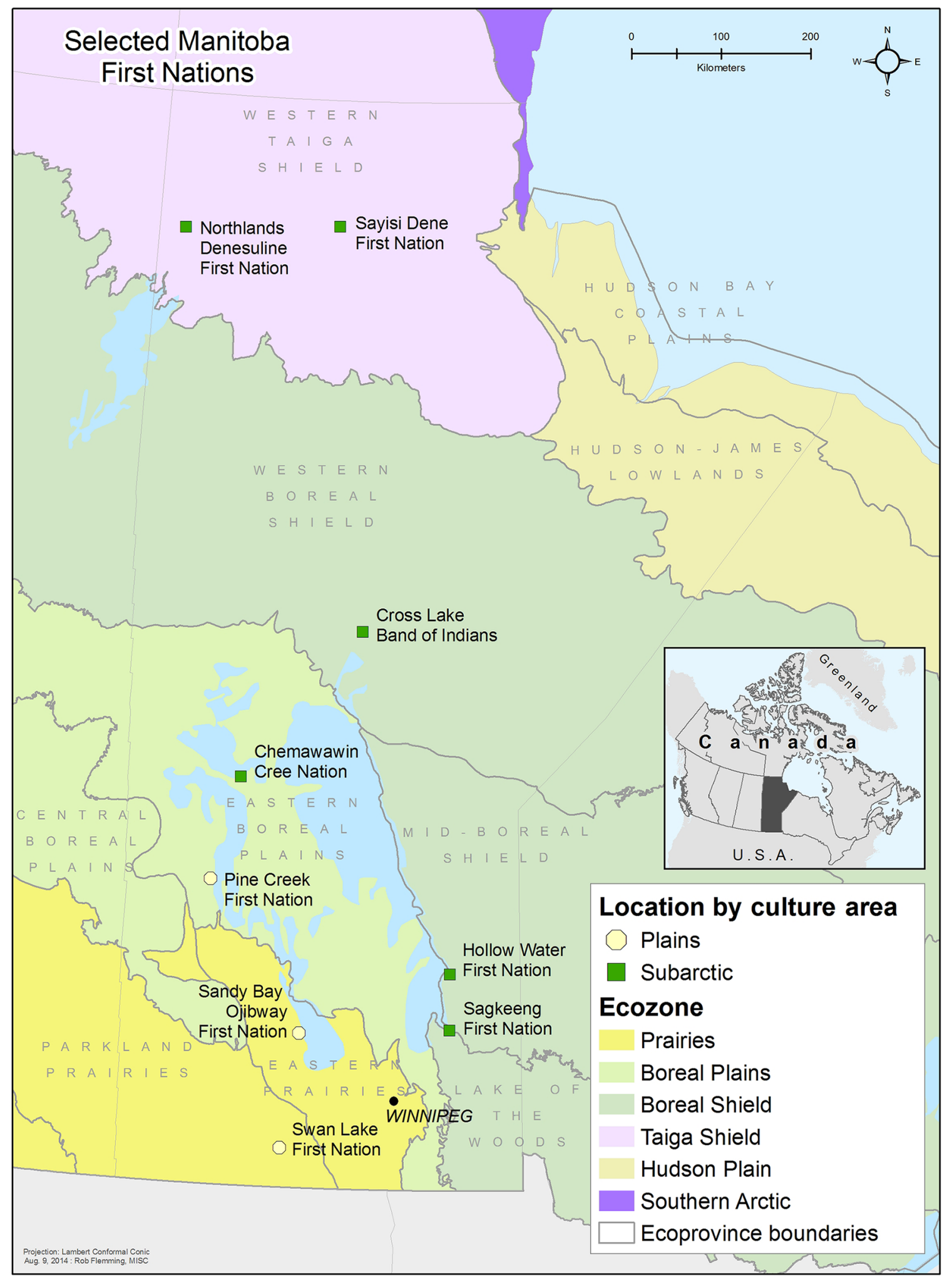

Fig. 1. Map of participating First Nations communities and ecozones (Chan et al. 2012). 
was approved by the ethics review boards at the University of Northern British Columbia, the University of Ottawa, the Université de Montreal, and Health Canada.

\section{Data collection}

Data were collected using an "in-person" household interview. A trained interviewer completed the survey with the participants; the survey was conducted in the participant's household and consisted of several questionnaires including a $24 \mathrm{~h}$ recall questionnaire; a traditional food frequency questionnaire (FFQ); and a socio-demographic, health, and lifestyle (SHL) questionnaire. The multi-pass technique with three stages was used to record the $24 \mathrm{~h}$ recall. In the first stage, a quick list of all foods and beverages consumed during the prior $24 \mathrm{~h}$ was built; in the second, a detailed description of the consumed foods and beverages (brands, amount eaten, etc.) was recorded; in the third, the recall was reviewed (Raper et al. 2004). A subsample of $20 \%$ of the participants were invited to complete a second $24 \mathrm{~h}$ recall for later analysis using the SIDE SAS (version 9.2) sub-routine to partially adjust for intra-individual variations that allows for a better approximation of the usual diet. To estimate corresponding intake quantities, three-dimensional food and beverage models were used. The FFQ was developed based on a comprehensive list of locally harvested traditional foods that was representative for each participating community. In Manitoba, the FFQ consisted of 153 traditional food items including 30 fish species. All participants provided information on traditional food consumption during the four seasons of the past year. Age- and gender-specific portion sizes of each traditional food item were determined from the $24 \mathrm{~h}$ recall data.

The SHL Questionnaire collected information on socio-demographic characteristics, lifestyle choices, and self-perceived health status. Body mass index (BMI) was calculated as weight (in kilograms) divided by the square of height (in meters). BMI categories were as follows: normal weight was characterized as a BMI $<25 \mathrm{~kg} / \mathrm{m}^{2}$, overweight was categorized as a BMI of $25 \mathrm{~kg} / \mathrm{m}^{2}$ or higher but $<30 \mathrm{~kg} / \mathrm{m}^{2}$, and obesity was categorized as a BMI $\geq 30 \mathrm{~kg} / \mathrm{m}^{2}$. Physical activity data were self-reported, and the study participants were asked to describe their physical activities based on the provided descriptions, as follows: (a) I am usually sitting and do not walk around very much; (b) I stand or walk around quite a lot, but I do not have to carry or lift things very often; (c) I usually lift or carry light loads or I have to climb stairs or walk up hills often; (d) I do heavy work or carry heavy loads.

\section{Assessment of T2D}

T2D was defined as a self-reported diagnosis of T2D via the SHL questionnaire. In addition, information on the type of diabetes (type 1,2) and the onset of the disease (i.e., how many years ago individuals were diagnosed with T2D) was collected. In this study, only those participants who reported being diagnosed with T2D were coded as cases of T2D (Huerta et al. 2009; Schneider et al. 2012). Participants with type 1 diabetes were grouped with those who did not have diabetes in the analysis.

Self-reported estimates of T2D in the FNFNES survey were validated by comparing the estimates with those reported by the Regional Health Survey (RHS), based on data collected between 2008 and 2010. The RHS is the only FNs-governed national health survey in Canada (AMC 2012). The weighted prevalence of diabetes reported by the FNFNES in Manitoba was 22\%, which was similar to the $21 \%$ reported by the RHS in Manitoba (AMC 2012).

\section{Fish sampling for contaminant content}

Fish samples collected for contaminant analyses were representative of all fish species consumed by members in each community. The fish sampling strategy was as follows: each community was to identify the most commonly consumed fish, identify the fish species that are of greatest concern from a 
nutrition and environmental perspective, and identify those fish species known to accumulate higher concentrations of contaminants (Chan et al. 2012). A total of eight fish species (bass, perch, pike, sturgeon, suckers, trout, walleye, and whitefish) were collected during the fall of 2010 (September through November). The collected fish samples were analyzed for POP including total PCB and DDE at Maxxam Analytics, formerly CANTEST, in Burnaby, British Columbia.

Replicate samples $(n=3-5)$ from each fish species from each community were homogenized to provide a homogeneous pooled sample for subsequent analysis. A total of 41 pooled fish samples were analyzed. If required, a moisture value was determined gravimetrically after drying a portion of the blended sample at $105{ }^{\circ} \mathrm{C}$ overnight. A modified US Environmental Protection Agency 1668C Method was used for extraction. Briefly, six grams of tissue was spiked with C-13 and deuteriumlabeled extraction internal standard and homogenized in dicloromethane (DCM), followed by Soxhlet extraction and filtered through anhydrous sodium sulphate. The extract was evaporated to $6 \mathrm{~mL}$, and $5 \mathrm{~mL}$ of it was injected onto the gel permeation chromatography column where a fraction of the eluent was collected, concentrated, and solvent exchanged to acetone:hexane (1:1). Further cleanup was performed by eluting this extract through multilayered silica gel and then alumina column chromatography. The final extract was concentrated and solvent exchanged to isooctane. Analysis was performed for DDE and PCB using gas chromatography mass spectrometry (GC-MS) in selective ion monitoring mode with an EI source (Agilent 7890 GC coupled to a 5975 mass spectrometer, Agilent Technologies, Santa Clara, California) based on US Environmental Protection Agency Method 680. All results were calculated by isotope dilution. Laboratory control samples and blank samples were measured for quality assurance/quality control. A total of 27 PCB congeners (PCB-1, 3, 4, 15, 19, 37, $54,77,81,104,105,114,118,123,126,155,156,157,167,169,188,189,202,205,206,208$, and 209) were measured and the sum was used to estimate total PCB concentrations.

\section{Estimation of fish, dietary POP (DDE, PCB), and long-chain omega-3 FAs intake}

Daily fish intake $(\mathrm{g} / \mathrm{d})$ was estimated using data from the FFQ by totaling the number of days in the past four seasons when fish consumption was reported (for each fish species). Then, the total number of days of reported fish intake was multiplied by the age- and gender-specific portion size of fish (g) estimated from dietary data generated by the $24 \mathrm{~h}$ recalls for each age and sex group, and divided by $360 \mathrm{~d}$ (in this study, a year included four seasons of $90 \mathrm{~d}$ each).

Total dietary PCB and DDE intake was calculated as follows: first, the amounts of PCB and DDE in each fish species (ng/g) were multiplied by the total amount of each fish species eaten per day (in grams); second, the amounts of PCB and DDE from all fish species consumed per day were totaled ( $\mathrm{g} / \mathrm{d})$ and divided by the body weight of each participant ( $\mathrm{ng} / \mathrm{kg}$ of body weight per day).

$\sum(\mathrm{PCB} \times$ fish intake $) /$ body weight

$\sum(\mathrm{DDE} \times$ fish intake $) /$ body weight

Community-specific data of POP content in fish species were used to calculate total PCB and DDE intake for each participant. Ecozone-specific concentrations of DDE and PCB content in fish species were used for the communities that were located within a particular ecozone if community-specific data were not available. Validation of the dietary assessments was performed through correlation analysis between mercury exposure from traditional food estimated using the FFQ and mercury concentrations in hair measured in FNs participants. Dietary mercury intake was correlated with mercury levels in hair. 
The Canadian File of Nutrients (Health Canada 2015) was used to determine the concentrations of n-3 FAs in all fish species reported by FNs in Manitoba. In this analysis, n-3 FAs refers to the combined EPA and DHA intake from consuming fish. The data are expressed as mg of EPA + DHA per gram of raw fish (mg/g). Raw values were used as fish tissue EPA + DHA concentrations may vary with cooking method. Using the raw values allows the comparison of our results with other studies. The total amount of EPA + DHA consumed by each participant based on fish intake (g/d) was calculated as follows:

$\sum[(\mathrm{EPA}+\mathrm{DHA}) \times$ fish intake $]$

The most consumed fish species in Manitoba were walleye, northern pike, lake whitefish, and lake trout. To define fish consumption patterns, the consumption of commonly consumed fish species as well as their contribution to dietary n-3 FAs, DDE, and PCB intake were described across four ecozones in Manitoba.

\section{Statistical analyses}

Descriptive statistics include the calculation of means with standard deviations (SDs) for continuous variables, and proportions for categorical variables. Medians (interquartile range) were calculated for skewed variables. Geometric means $(95 \% \mathrm{CI})$ were estimated for dietary DDE and PCB intake. Student's $t$ tests, analysis of variance (ANOVA), and $\chi^{2}$ tests were used to test if differences between groups were statistically significant. Sub-group stratified analyses by gender, age groups, and ecozones were performed to describe the study population by diabetes status. Fish consumption was categorized into four groups: no or $<1 /$ month, $1 /$ month, $2-3 /$ month, and $\geq 1 /$ week to examine dose-response relationship between fish consumption and T2D prevalence. We chose $150 \mathrm{~g}$ as the fish portion size in this analysis because this amount represents two servings (75 $\mathrm{g}$ each) of fish per week as recommended by Canada's Food Guide - FNs, Inuit and Métis (Health Canada 2007). Pearson's correlation coefficients were investigated among all continuous predictors. Collinearity was observed between fish consumption with n-3 FAs intake, and n-3 FAs intake with PCB and DDE.

Simple logistic regression models were used to explore the relationships between an outcome (T2D) and each individual primary predictor of interest (fish intake (categorical), PCB, DDE (continuous), n-3 FAs (continuous and categorical)), as well as all potential confounders (age, gender, BMI, total energy intake (obtained from $24 \mathrm{~h}$ recall), smoking, physical activity, household size (number of people per household), and years of education).

Multiple logistic regression models adjusted for potential covariates were developed to investigate the associations between each of the following factors and the prevalence of T2D: total fish intake, dietary POP (PCB and DDE), and n-3 FAs (EPA + DHA) intake. Independent variables such as DDE, PCB, and n-3 FAs did not fit a normal distribution and were normalized using the natural logarithmic function. POP concentrations below the limit of quantification were imputed with half the limit of detection (LOD) of PCB and DDE to avoid errors in the analysis. The LOD of DDE is $0.0005 \mu \mathrm{g} / \mathrm{g}$ and the LOD of PCB is $0.0003 \mu \mathrm{g} / \mathrm{g}$ (Chan et al. 2012).

Three models were developed to analyze the association between the frequency of fish consumption (four categories) and T2D prevalence. Adjustment variables were selected based on well-established risk factors for T2D reported in the literature including age, sex, body mass index (BMI), smoking, physical activity, total energy intake, education, and household size. Covariates were added to the models gradually to evaluate their relative contribution to the association between the predictors of interest and the outcome variable. Model 1 was adjusted for age, gender, and BMI; Model 2 was additionally adjusted for physical activity, total energy intake, smoking, household size, and education; 
Model 3 was controlled for covariates in Model 2 and DDE/PCB intake to eliminate their possible effect on T2D. Age, BMI, energy intake, number of people per household, and years of education were treated as continuous variables, whereas gender, smoking, and physical activity were categorical variables. Fat, saturated fat, carbohydrate, fruit, and vegetable intake were also considered as covariates but were removed from the models because they did not change the value of the association between $\mathrm{T} 2 \mathrm{D}$ and fish consumption.

Logistic regression models were developed to analyze the relationships between log-transformed dietary DDE, PCB, and n-3 FAs intake and T2D prevalence, both overall and stratified by age group ( $<45$ years; $\geq 45$ years). We chose the age of 45 as the division between the groups as it was close to the median age of the study population, across different regions of Canada.

The models were tested for interactions between predictors $\left(x_{1}, x_{2}\right)$ by including the product " $x_{1} \times x_{2}$ " as an additional predictor in a model containing $x_{1}$ and $x_{2}$ :

$\log \left(p(y) /(1-p(y))=\beta_{0}+\beta_{1} x_{1}+\beta_{2} x_{2}+\beta_{3} x_{1} \times x_{2}\right.$

No interaction was detected.

Results with a $p$-value of $<0.05$ were considered statistically significant. All statistical analyses were performed using weighting variables to obtain representative estimates at the regional level. JMP version 11 and $\mathrm{R}$ software were used to conduct the statistical analyses.

Sensitivity analyses were conducted to explore differences in dietary characteristics and physical activity between responders who were recently diagnosed with T2D ( $\leq 5$ years ago) and those who have had T2D for a long period of time ( $>5$ years) (Table S1). In addition, analyses of dietary and lifestyle practice by dieting status were performed between participants with and without T2D (Table S2).

\section{Results}

This study included 706 participants (477 women and 229 men). Participant ages ranged from 19 to 96 years, with a mean age of 43.4 years. Descriptive characteristics of Manitoba participants by diabetes status are presented in Table 1 . The prevalence of diagnosed T2D was 22\%. When standardized to the 2015 Canadian population, the prevalence of T2D was $28.4 \%$. Participants with T2D were more likely to be older, male, to have a higher BMI, and to be less physically active and less educated than those without T2D. Some differences in dietary intake were noted between diabetic and non-diabetic participants: individuals with T2D reported significantly lower intakes of total energy, total fat, and carbohydrate. Fruit and vegetable consumption was very low among all Manitoba participants $(9.9 \mathrm{~g} / \mathrm{d})$, and was comparable between diabetic $(10.2 \mathrm{~g} / \mathrm{d})$ and non-diabetic participants $(9.8 \mathrm{~g} / \mathrm{d})$.

Overall, $82 \%$ of participants reported the consumption of fish at least once in the prior year. The mean intake of total fish in the study population was $9.2 \mathrm{~g} / \mathrm{d}$ (median $2.7 \mathrm{~g} / \mathrm{d}$; range $0-230 \mathrm{~g} / \mathrm{d}$ ). Individuals with T2D consumed $11.6 \mathrm{~g} / \mathrm{d}$ of fish, whereas those without T2D reported eating $8.5 \mathrm{~g} / \mathrm{d}$ of fish. The intake of long-chain n-3 FAs (EPA + DHA) was slightly higher in participants with T2D than those without the disease ( $69 \mathrm{mg} / \mathrm{d}$ vs. $42 \mathrm{~g} / \mathrm{d}$, respectively). The mean intake of DDE and PCB was very low in both groups. Significant differences in fish consumption were found between men and women (16.7 g/d vs. $5.2 \mathrm{~g} / \mathrm{d}$, respectively).

Table 2 presents the characteristics of participants by age group ( $<45$ years vs. $\geq 45 y e a r s)$. The prevalence of T2D was higher in older responders (36.8\%) than younger participants (10\%). Mean BMI was comparable between the two groups, whereas physical activity was lower in older subjects. In addition, 
Table 1. Characteristics of Manitoba First Nations adults by diabetic status $(n=706)$.

\begin{tabular}{|c|c|c|c|}
\hline & With T2D & Without T2D & $p$-value \\
\hline$N,(\%)$ & $123(22)$ & $583(78)$ & - \\
\hline Women, $n(\%)$ & $76(20)$ & $401(80)$ & 0.13 \\
\hline Men, $n(\%)$ & $47(26)$ & $182(74)$ & 0.11 \\
\hline Age & $52.71(49.14-56.28)$ & $40.73(37.04-44.41)$ & 0.0001 \\
\hline Smoking, $n(\%)$ & $61(50)$ & $383(66)$ & 0.0008 \\
\hline Dieting, $n(\%)$ & $10(10.1)$ & $50(7.5)$ & 0.87 \\
\hline BMI $\left(\mathrm{kg} / \mathrm{m}^{2}\right)$ & $33.11(30.52-35.71)$ & $30.03(29.33-30.73)$ & 0.0001 \\
\hline Household size & $5.71(4.72-6.69)$ & $5.4(64.74-6.18)$ & 0.35 \\
\hline Years of education & $8.88(8.26-9.50)$ & $10.08(9.64-10.51)$ & 0.0003 \\
\hline Employment, any (\%) & $62(60.8)$ & $323(61.7)$ & 0.27 \\
\hline Age groups, $n$ (\%) & & & 0.0001 \\
\hline $19-30$ & $9(6.5)$ & $165(25.9)$ & - \\
\hline $31-50$ & $50(37.9)$ & $287(53.3)$ & - \\
\hline $51-70$ & $56(48.2)$ & $115(16.8)$ & - \\
\hline $71+$ & $8(7.5)$ & $16(3.9)$ & - \\
\hline BMI category, $n$ (\%) & & & 0.0001 \\
\hline$<25$ & $7(8)$ & $142(22.2)$ & - \\
\hline $25-29.99$ & $31(25.6)$ & $182(31.6)$ & - \\
\hline$\geq 30$ & $85(66.4)$ & $259(46.3)$ & - \\
\hline Physical activity, $n$ (\%) & & & 0.0007 \\
\hline Inactive & $45(35.2)$ & $115(17.8)$ & - \\
\hline Sedentary & $50(37.2)$ & $307(53.8)$ & - \\
\hline Moderate & $20(18.6)$ & $104(18.9)$ & - \\
\hline Vigorous & $8(9.1)$ & $57(9.5)$ & - \\
\hline Diploma, $n$ (\%) & & & 0.38 \\
\hline Less than high school & $72(62.4)$ & $341(58.5)$ & - \\
\hline High school & $31(21.3)$ & $174(28.3)$ & - \\
\hline Post-secondary & $20(16.3)$ & $68(13.3)$ & - \\
\hline \multicolumn{4}{|l|}{ Dietary characteristics } \\
\hline Energy intake (kcal/d) & 1807.8 (1439.6-1975.9) & $2027.9(1818.6-2237.3)$ & 0.020 \\
\hline Fruit/vegetables (g/d) & $10.24(5.48-19.11)$ & $9.81(6.89-13.95)$ & 0.051 \\
\hline Total fat $(\mathrm{g} / \mathrm{d})$ & $59.22(33-92.51)$ & $75.78(47.81-106.89)$ & 0.012 \\
\hline Saturated Fat (g/d) & $18.68(11.07-28.15)$ & $22.76(14.68-33.94)$ & 0.031 \\
\hline Carbohydrate (g/d) & $172.2(107.8-275.1)$ & $223.1(157.8-315.9)$ & 0.020 \\
\hline
\end{tabular}


Table 1. (concluded)

\begin{tabular}{lccc} 
& With T2D & Without T2D & $p$-value \\
\hline Protein (g/d) & $68(45-100)$ & $71.08(47.83-100.55)$ & 0.78 \\
Total fish intake (g/d) & $11.6(3.1-26.4)$ & $8.5(1.7-15.3)$ & 0.06 \\
\hline DDE (ng/kg per day) & $0.003(0.001-0.02)$ & $0.002(0.001-0.01)$ & 0.09 \\
PCB (ng/kg per day) & $0.001(0.00-0.01)$ & $0.001(0.00-0.004)$ & 0.33 \\
EPA + DHA (mg/day) & $69.08(35.11-173.26)$ & $41.9(61.65-82.27)$ & 0.41 \\
\hline
\end{tabular}

Note: BMI, body mass index; DDE, dichlorodiphenyldichloroethylene; PCB, polychlorinated biphenyls; EPA, eicosapentaenoic acid; DHA, docosahexaenoic acid; T2D, type 2 diabetes. Values reported are the mean $(95 \% \mathrm{CI})$; DDE and PCB values reported are the geometric mean; $p$-values correspond to $t$ tests for continuous variables and $\chi^{2}$ tests for categorical variables; weighted estimates.

Table 2. Characteristics of Manitoba participants by age group ( $<45$ years $/ \geq 45$ years).

\begin{tabular}{|c|c|c|c|}
\hline & $<45$ & $\geq 45$ & $p$-value \\
\hline$n$ & 709 & 717 & - \\
\hline T2D (\%) & 10 & 36.8 & 0.0001 \\
\hline $\operatorname{BMI}\left(\mathrm{kg} / \mathrm{m}^{2}\right)$ & $30.7(29.9-31.4)$ & $31.4(30.8-32.1)$ & 0.148 \\
\hline Smoking (\%) & 60.8 & 36.7 & 0.0001 \\
\hline Physical activity (\%) & & & 0.0002 \\
\hline Inactive & 16.1 & 23.5 & - \\
\hline Sedentary & 40.6 & 44.9 & - \\
\hline Moderate & 28.4 & 23.4 & - \\
\hline Vigorous & 14.9 & 8.2 & - \\
\hline \multicolumn{4}{|l|}{ Dietary characteristics } \\
\hline Total energy (kcal/d) & $1982(1355-2494)$ & $1730(1193-2210)$ & 0.001 \\
\hline Fruit/vegetables (g/d) & $7.3(5.4-9.8)$ & $14.4(7.2-29.0)$ & 0.002 \\
\hline Fat $(\mathrm{g} / \mathrm{d})$ & $84.8(75.7-93.9)$ & $74.4(66.2-82.5)$ & 0.002 \\
\hline Protein $(\mathrm{g} / \mathrm{d})$ & $68.1(45.9-100.4)$ & $73.4(49.4-105.1)$ & 0.55 \\
\hline Carbohydrate (g/d) & $244.2(168.8-335.7)$ & $188.5(120.7-275.1)$ & 0.001 \\
\hline Fish intake $(\mathrm{g} / \mathrm{d})$ & $6.3(2.5-10.5)$ & $12.7(1.0-26.3)$ & 0.002 \\
\hline DDE (n/kg per day) & $0.002(0-0.01)$ & $0.004(0.0-0.03)$ & 0.07 \\
\hline PCB (n/kg per day) & $0.001(0.0-0.002)$ & $0.002(0.0-0.01)$ & 0.14 \\
\hline $\mathrm{EPA}+\mathrm{DHA}(\mathrm{mg} / \mathrm{d})$ & $32.0(5.4-58.8)$ & $67.3(15.6-150.4)$ & 0.001 \\
\hline
\end{tabular}

Note: T2D, type 2 diabetes; BMI, body mass index; DDE, dichlorodiphenyldichloroethylene; PCB, polychlorinated biphenyls; EPA, eicosapentaenoic acid; DHA, docosahexaenoic acid. Values reported are the mean (95\% CI); DDE and PCB values reported are the geometric mean; $p$-values correspond to $t$ tests for continuous variables and $\chi^{2}$ tests for categorical variables; weighted estimates. 
individuals aged 45 years and over reported lower total energy, fat, and carbohydrate intake, but greater fruit, vegetable, and fish consumption.

Table 3 shows the characteristics of the participants by frequency of fish intake. More frequent fish consumption was associated with lower prevalence of self-reported T2D, older age, being male, and higher physical activity.

Description of fish consumption patterns and long-chain n-3 FAs and DDE/PCB intake in four Manitoba ecozones (Prairies/Plains, Boreal Plains, Boreal Shield, and Taiga Shield) are summarized in Table 4. Overall, the consumption of 30 different types of fish was reported by Manitoba FNs participants. The most consumed fish species across all Manitoba ecozones were walleye, lake whitefish, northern pike, and lake trout, which constituted $78 \%$ of the total fish intake. Geographical differences in the amount and type of fish consumed were noted in four ecozones. The highest total fish intake was reported by participants living in the northern Taiga Shield/Subarctic ecozone with a mean intake

Table 3. Characteristics of Manitoba participants by frequency of fish consumption.

\begin{tabular}{|c|c|c|c|c|c|}
\hline & 0 or $<1 /$ month & $1 /$ month & $2-3 /$ month & $\geq 1 /$ week & $p$-value \\
\hline$n$ & 225 & 232 & 163 & 86 & - \\
\hline T2D (\%) & 20 & 19 & 15 & 12 & 0.35 \\
\hline Age (year) & $41.0(34.6-47.3)$ & $45.0(43.2-46.8)$ & $41.3(38.7-44.0)$ & $49.9(41.6-58.2)$ & 0.04 \\
\hline Women (\%) & 82 & 71 & 55 & 44 & 0.0001 \\
\hline Men (\%) & 18 & 29 & 45 & 56 & 0.0001 \\
\hline BMI $\left(\mathrm{kg} / \mathrm{m}^{2}\right)$ & $30.6(28.8-32.4)$ & $30.9(30.2-31.6)$ & $31.4(29.8-33.0)$ & $29.5(27.6-31.3)$ & 0.08 \\
\hline Smoking (\%) & 68 & 57 & 64 & 63 & 0.12 \\
\hline Physical activity (\%) & & & & & 0.001 \\
\hline Sedentary & 79 & 70 & 74 & 67 & - \\
\hline Moderate & 12 & 23 & 19 & 14 & - \\
\hline Vigorous & 9 & 7 & 7 & 19 & - \\
\hline \multicolumn{6}{|l|}{ Dietary characteristics } \\
\hline Total energy $(\mathrm{kcal} / \mathrm{d})$ & $1931.4(1614.1-2248.7)$ & $1861.5(1623.5-2099.5)$ & $2060.2(1791.9-2328.5)$ & $2046.3(1643.6-2448.9)$ & 0.81 \\
\hline Fruit/vegetables $(\mathrm{g} / \mathrm{d})$ & $6.3(3.6-11.1)$ & $14.3(5.5-37.0)$ & $13(5.4-31.5)$ & $9.3(5.7-15.1)$ & 0.49 \\
\hline Fat $(\mathrm{g} / \mathrm{d})$ & $76.6(63.7-89.5)$ & $76.5(69.3-83.7)$ & $87(71.9-102.1)$ & $85(64.1-106.0)$ & 0.18 \\
\hline Protein $(\mathrm{g} / \mathrm{d})$ & $68.7(57.9-79.5)$ & $73.4(64.0-82.7)$ & $92.2(80.5-103.9)$ & $97.3(83.0-111.7)$ & 0.005 \\
\hline Carbohydrate $(\mathrm{g} / \mathrm{d})$ & $246.5(201.2-291.8)$ & $224.3(183.9-264.8)$ & $232.7(201.2-264.3)$ & $230.9(191.0-270.7)$ & 0.04 \\
\hline Fish intake $(\mathrm{g} / \mathrm{d})$ & $0.3(0.2-0.4)$ & $2.6(2.4-2.9)$ & $9.6(8.4-10.7)$ & $45.6(36.0-55.2)$ & 0.0001 \\
\hline $\mathrm{DDE}(\mathrm{n} / \mathrm{kg}$ per day) & $0.0(0.0-0.0)$ & $0.003(0.0-0.032)$ & $0.053(0.002-0.71)$ & $1.47(0.003-7.38)$ & 0.0001 \\
\hline PCB (n/kg per day) & $0.0(0.0-0.0)$ & $0.001(0.0-0.003)$ & $0.008(0.001-0.08)$ & $0.69(0.002-2.39)$ & 0.0001 \\
\hline $\mathrm{EPA}+\mathrm{DHA}(\mathrm{mg} / \mathrm{d})$ & $1.4(1.2-1.7)$ & $9.9(7.8-12.0)$ & $45.6(29.1-62.1)$ & $253(149.0-356.9)$ & 0.0001 \\
\hline
\end{tabular}

Note: T2D, type 2 diabetes; BMI, body mass index; DDE, dichlorodiphenyldichloroethylene; PCB, polychlorinated biphenyls; EPA, eicosapentaenoic acid; DHA, docosahexaenoic acid. Values reported are the mean (95\% CI); DDE and PCB values reported are the geometric mean; sedentary physical activity combines inactive and sedentary lifestyles; $p$-values correspond to ANOVA for continuous variables and $\chi^{2}$ tests for categorical variables; weighted estimates. 
Table 4. Fish consumption patterns and dietary characteristics by ecozone in Manitoba.

\begin{tabular}{|c|c|c|c|c|c|}
\hline & $\begin{array}{l}\text { Prairies/Plains, } \\
\text { Prairies/Subarctic }\end{array}$ & $\begin{array}{l}\text { Boreal Plains, } \\
\text { Plains/Subarctic }\end{array}$ & $\begin{array}{c}\text { Boreal } \\
\text { Shield/Subarctic }\end{array}$ & $\begin{array}{c}\text { Taiga } \\
\text { Shield/Subarctic }\end{array}$ & $p$-value \\
\hline$n$ & 170 & 187 & 232 & 117 & - \\
\hline T2D (\%) & 19.8 & 31.3 & 18.6 & 5.1 & 0.0001 \\
\hline Age (year) & $42 \pm 13.7$ & $43 \pm 13.8$ & $43 \pm 15.5$ & $40 \pm 13.9$ & 0.22 \\
\hline BMI $\left(\mathrm{kg} / \mathrm{m}^{2}\right)$ & $29.8 \pm 6.2$ & $31.3 \pm 6.7$ & $30.4 \pm 6.4$ & $29.1 \pm 6.2$ & 0.016 \\
\hline Women (\%) & 62 & 71 & 66 & 72 & 0.24 \\
\hline Energy intake (kcal/d) & $1884(1256-3072)$ & $1766(1273-2349)$ & 1795 (1265-2358) & $1642(1279-2421)$ & 0.16 \\
\hline Smoking (\%) & 71 & 59 & 53 & 77 & 0.0001 \\
\hline Physical activity (\%) & & & & & 0.57 \\
\hline Moderate/vigorous & 27 & 30 & 27 & 23 & 0.57 \\
\hline \multicolumn{6}{|l|}{ Dietary characteristics } \\
\hline Fish consumers (\%) & 68 & 94 & 80 & 92 & 0.01 \\
\hline Total fish intake $(\mathrm{g} / \mathrm{d})$ & $2.2(0.14-60.0)$ & $3.3(0.4-50.0)$ & $3.7(0.4-81.6)$ & $13.5(0.5-166.2)$ & 0.0001 \\
\hline DDE (ng/kg per day) & $0.001(0-0.25)$ & $0.001(0-0.29)$ & $0.001(0-1.22)$ & $0.46(0-5.5)$ & 0.0001 \\
\hline PCB (ng/kg per day) & $0.001(0-0.28)$ & $0.001(0-0.30)$ & $0.001(0-1.08)$ & $0.62(0-7.33)$ & 0.0001 \\
\hline $\mathrm{EPA}+\mathrm{DHA}(\mathrm{g} / \mathrm{d})$ & $0.007(0.001-0.26)$ & $0.01(0.002-0.19)$ & $0.01(0.004-0.5)$ & $0.1(0.005-1.41)$ & 0.0001 \\
\hline Walleye consumers (\%) & 60 & 66 & 69 & 66 & 0.28 \\
\hline Walleye (g/d) & $1.9(0.2-30.2)$ & $2.3(0.3-43.8)$ & $2.2(0.3-32.3)$ & $3.2(0.3-26.6)$ & 0.02 \\
\hline DDE (ng/kg per day) & 0.00 & 0.00 & 0.00 & 0.00 & - \\
\hline PCB (ng/kg per day) & 0.00 & 0.00 & 0.00 & 0.00 & - \\
\hline $\mathrm{EPA}+\mathrm{DHA}(\mathrm{g} / \mathrm{d})$ & $0.01(0.001-0.09)$ & $0.01(0.001-0.14)$ & $0.001(0.001-0.1)$ & $0.01(0.001-0.08)$ & 0.02 \\
\hline Northern pike consumers (\%) & 24 & 26 & 29 & 28 & 0.74 \\
\hline Northern pike (g/d) & $1.5(0.2-32.3)$ & $1.6(0.1-53.7)$ & $1.6(0.3-29.0)$ & $2.3(0.14-27.8)$ & 0.34 \\
\hline DDE (ng/kg per day) & $0.001(0-0.09)$ & $0.001(0-0.13)$ & $0.001(0-0.21)$ & $0.001(0-0.12)$ & 0.63 \\
\hline PCB (ng/kg perday) & $0.001(0-0.04)$ & $0.001(0-0.05)$ & $0.001(0-0.08)$ & $0.001(0-0.05)$ & 0.71 \\
\hline $\mathrm{EPA}+\mathrm{DHA}(\mathrm{g} / \mathrm{d})$ & $0.004(0.0004-0.09)$ & $0.004(0.0004-0.16)$ & $0.005(0.001-0.09)$ & $0.01(0.0004-0.09)$ & 0.33 \\
\hline Whitefish consumers (\%) & 16 & 28 & 26 & 47 & 0.0001 \\
\hline Lake whitefish (g/d) & $2.05(0.14-55.9)$ & $1.7(0.2-88.9)$ & $2.2(0.14-50.0)$ & $4.1(0.39-61.2)$ & 0.16 \\
\hline DDE (ng/kg per day) & $0.02(0-0.73)$ & $0.02(0-1.43)$ & $0.02(0-0.67)$ & $0.02(0-0.95)$ & 0.81 \\
\hline PCB (ng/kg per day) & $0.001(0-0.22)$ & $0.001(0-0.43)$ & $0.001(0-0.2)$ & $0.001(0-0.29)$ & 0.42 \\
\hline $\mathrm{EPA}+\mathrm{DHA}(\mathrm{g} / \mathrm{d})$ & $0.03(0.002-0.88)$ & $0.03(0.003-1.40)$ & $0.03(0.002-0.78)$ & $0.06(0.01-0.96)$ & 0.16 \\
\hline Lake trout consumers (\%) & 8 & 12 & 13 & 33 & 0.0001 \\
\hline Lake trout $(\mathrm{g} / \mathrm{d})$ & $5.4(0.5-37.1)$ & $2.7(0.14-23.3)$ & $6.5(0.14-62.6)$ & $4.3(0.14-83.4)$ & 0.27 \\
\hline DDE (ng/kg per day) & $0.42(0.03-6.96)$ & $0.29(0.01-2.45)$ & $0.73(0.01-4.73)$ & $0.46(0.02-6.56)$ & 0.26 \\
\hline
\end{tabular}


Table 4. (concluded)

\begin{tabular}{lcccc} 
& $\begin{array}{c}\text { Prairies/Plains, } \\
\text { Prairies/Subarctic }\end{array}$ & $\begin{array}{c}\text { Boreal Plains, } \\
\text { Plains/Subarctic }\end{array}$ & $\begin{array}{c}\text { Boreal } \\
\text { Shield/Subarctic }\end{array}$ & $\begin{array}{c}\text { Taiga } \\
\text { Shield/Subarctic }\end{array}$ \\
\hline PCB (ng/kg per day) & $0.63(0.04-3.26)$ & $0.41(0.01-3.54)$ & $0.85(0.02-6.83)$ & $0.64(0.01-9.49)$ \\
EPA + DHA (g/d) & $0.05(0.004-0.36)$ & $0.03(0.001-0.23)$ & $0.06(0.001-0.61)$ & $0.04(0.001-0.8)$ \\
\hline
\end{tabular}

Note: T2D, type 2 diabetes; BMI, body mass index; DDE, dichlorodiphenyldichloroethylene; PCB, polychlorinated biphenyls; EPA eicosapentaenoic acid; DHA, docosahexaenoic acid; ng/kg per day, nanograms per $\mathrm{kg}$ of body weight per day. Data reported are the mean \pm SD or median (2.5-97.5th percentiles). Fish, DDE, PCB and EPA + DHA intakes estimated for fish consumers only; $p$-values correspond to ANOVA for continuous variables and $\chi^{2}$ tests for categorical variables; weighted estimates of T2D prevalence.

of $25.6 \mathrm{~g} / \mathrm{d}$ (median, $13.5 \mathrm{~g} / \mathrm{d}$ ) compared with only $11.4 \mathrm{~g} / \mathrm{d}$ (median, $3.7 \mathrm{~g} / \mathrm{d}$ ) in the Boreal Shield, $5.8 \mathrm{~g} / \mathrm{d}$ (median, $2.2 \mathrm{~g} / \mathrm{d}$ ) in the Prairies/Plains, and $5.9 \mathrm{~g} / \mathrm{d}$ (median, $3.3 \mathrm{~g} / \mathrm{d}$ ) in the Boreal Plains. Walleye was the most consumed fish species of all fish consumed, with the proportion of consumption varying from $60 \%$ to $69 \%$ across four ecozones. The lowest total fish intake and the greatest number of consumed fish species were reported by participants in the Prairies/Plains ecozone. Lake trout was the primary contributor to DDE and PCB intake. Nevertheless, lake trout and lake whitefish were the main sources of EPA and DHA. There were differences in the prevalence of T2D across the Manitoba ecozones. In the Taiga Shield, only 5\% of individuals reported being diagnosed with T2D, whereas in the other three regions reported prevalence ranged from $18 \%$ to $31 \%$. The mean BMI, physical activity, and total energy intake were comparable among participants across the four Manitoba ecozones.

Table 5 presents the multiple logistic regression analysis of the association between the frequency of fish consumption and T2D prevalence. Dose-response associations were observed across the frequency of fish intake and T2D prevalence. Model 1 was adjusted for age, gender, and BMI only. Model 2 was additionally adjusted for other covariates such as physical activity (categorical), total energy intake (continuous), smoking (yes/no), household size (continuous), and years of education (continuous). Model 3 was further controlled for DDE/PCB intake to examine whether the relationship between fish intake and T2D prevalence was mediated by DDE and PCB in fish. The results from all the models showed statistically significant inverse associations between fish consumption of

Table 5. Multiple logistic regression analyses of fish consumption and type 2 diabetes.

\begin{tabular}{lcccc} 
& \multicolumn{4}{c}{ No. of servings } \\
\cline { 2 - 5 } & No or $<\mathbf{1}$ /month & 1/month & 2-3/month & $\geq 1$ /week \\
Model 1 & 1 (ref) & $0.76(0.25-2.20)$ & $0.51(0.26-0.97)^{a}$ & $0.49(0.26-0.91)^{a}$ \\
Model 2 & 1 (ref) & $0.77(0.25-2.32)$ & $0.52(0.28-0.96)^{a}$ & $0.51(0.31-0.84)^{b}$ \\
\hline Model 3 & 1 (ref) & $0.77(0.25-2.31)$ & $0.51(0.28-0.91)^{a}$ & $0.40(0.19-0.82)^{b}$ \\
$n$ & 247 & 191 & 165 & 103 \\
\hline
\end{tabular}

Note: OR, odds ratio; BMI, body mass index; DDE, dichlorodiphenyldichloroethylene; PCB, polychlorinated biphenyls. Values reported are OR (95\% CI). Model 1: adjusted for age, gender, and BMI; Model 2: additionally adjusted for physical activity, total energy intake, smoking, household size, and education; Model 3: adjusted for Model 2 and DDE/PCB (tertiles). Portion size is $150 \mathrm{~g}$ of fish. ${ }^{a} p$-value $<0.05$. ${ }^{b} p$-value $<0.01$. 
$2-3$ portions per month with an odds ratio $(\mathrm{OR})=0.51$ (95\% CI: $0.28-0.91)$ and $\geq 1 /$ week with an OR $=0.40$ (95\% CI: 0.19-0.82) and T2D prevalence when compared with no consumption or consumption of less than one portion of fish per month.

Multiple logistic regressions of log-transformed DDE, $\mathrm{PCB}$, and EPA + DHA intakes with the prevalence of T2D both overall and stratified by age group are presented in Table 6. DDE, PCB, and EPA + DHA variables were not normally distributed, and so were normalized using the natural logarithmic function. Two models were developed. Model 1 was adjusted for potential covariates: age, BMI, gender, energy intake, physical activity, smoking, household size, and years of education. In Model 2, DDE and PCB were additionally adjusted for EPA + DHA intake, whereas $\mathrm{EPA}+\mathrm{DHA}$ was controlled for DDE/PCB intake. There were no associations between DDE and $\mathrm{PCB}$ intake with T2D prevalence in both the overall and stratified by age group analyses. However, an inverse association between EPA + DHA intake and T2D prevalence was found among younger participants in the model controlled for DDE/PCB intake, and in both models among older individuals. When EPA + DHA intake was stratified by tertiles (Table 7), the highest intake of EPA + DHA showed statistically significant protective effects on T2D prevalence with $\mathrm{OR}=0.48$ (95\% CI: $0.30-0.77)$ compared with the reference group.

Table 8 presents concentrations of POP and n-3 FAs (EPA + DHA) in the four most consumed fish species in Manitoba. The concentration of DDE and PCB was not detected in walleye across the four Manitoba ecozones. In northern pike, PCB and DDE were detected only in the Boreal Shield. Lake whitefish contained low concentrations of DDE ranging from 0.65 to $1.61 \mathrm{ng} / \mathrm{g}$, and PCB ranging from 0.17 to $0.33 \mathrm{ng} / \mathrm{g}$. Lake trout had the highest POP concentrations across the four regions compared with other species (DDE: 7.65-15.8 ng/g; PCB: 7.41-11.06 ng/g). There were no statistically significant differences in PCB and DDE concentrations in the four most consumed fish species

Table 6. Logistic regression analyses of log-transformed intake of DDE, PCB, and long-chain n-3 fatty acids and the prevalence of type 2 diabetes in the total sample and stratified by age group.

\begin{tabular}{|c|c|c|c|}
\hline & DDE & PCB & EPA + DHA \\
\hline \multicolumn{4}{|c|}{ Total population } \\
\hline Model 1 & $0.97(0.8-1.1)$ & $0.94(0.8-1.04)$ & $0.93(0.8-1.07)$ \\
\hline Model 2 & $1.04(0.8-1.3)$ & $0.97(0.8-1.1)$ & $0.87(0.6-1.18)$ \\
\hline \multicolumn{4}{|c|}{$<45$ years } \\
\hline Model 1 & $0.96(0.78-1.17)$ & $0.90(0.74-1.28)$ & $0.97(0.64-1.05)$ \\
\hline Model 2 & $0.99(0.76-1.29)$ & $0.96(0.63-1.32)$ & $0.95^{a}(0.59-0.99)$ \\
\hline \multicolumn{4}{|c|}{$\geq 45$ years } \\
\hline Model 1 & $0.98(0.82-1.16)$ & $0.97(0.79-1.17)$ & $0.85^{a}(0.63-0.99)$ \\
\hline Model 2 & $1.14(0.87-1.48)$ & $1.08(0.86-1.34)$ & $0.75^{a}(0.41-0.92)$ \\
\hline
\end{tabular}

Note: OR, odds ratio; DDE, dichlorodiphenyldichloroethylene; PCB, polychlorinated biphenyls; EPA, eicosapentaenoic acid; DHA, docosahexaenoic acid. Values reported are OR (95\% CI). Model 1: adjusted for age, BMI, gender, energy intake, physical activity, smoking, household size, education; Model 2: DDE and PCB were additionally adjusted for EPA + DHA intake. $\mathrm{EPA}+\mathrm{DHA}$ was adjusted for DDE/PCB; OR values: per unit change in regression (log transformed variables).

${ }^{a} p$-value $<0.05$. 
Table 7. Multiple logistic regression analyses of intake of long-chain n-3 fatty acids and type 2 diabetes.

\begin{tabular}{cccc} 
& \multicolumn{3}{c}{ Tertile } \\
\cline { 2 - 4 } & 1 & 2 & 3 \\
Model 1 & 1 (ref) & $0.72(0.28-1.86)$ & $0.49^{a}(0.29-0.83)$ \\
Model 2 & 1 (ref) & $0.80(0.46-1.33)$ & $0.53^{a}(0.33-0.84)$ \\
Model 3 & 1 (ref) & $0.77(0.28-2.12)$ & $0.48^{a}(0.30-0.77)$ \\
\hline
\end{tabular}

Note: OR, odds ratio; BMI, body mass index; DDE, dichlorodiphenyldichloroethylene; PCB, polychlorinated biphenyls. Values reported are OR (95\% CI). Model 1: adjusted for age, BMI, gender; Model 2: further adjusted for energy intake, physical activity, smoking, education, and household size; Model 3: adjusted for Model $2+$ DDE/PCB.

${ }^{a} p$-value $<0.01$.

Table 8. Concentrations of n-3 fatty acids and persistent organic pollutants in the most consumed fish species in Manitoba ecozones.

\begin{tabular}{|c|c|c|c|c|c|c|c|c|c|}
\hline \multirow[b]{3}{*}{ Fish species } & \multirow[b]{3}{*}{$\mathrm{EPA}+\mathrm{DHA}(\mathrm{g} / 100 \mathrm{~g})$} & \multicolumn{8}{|c|}{ Ecozones } \\
\hline & & \multicolumn{2}{|c|}{$\begin{array}{c}\text { Prairies/Plains, } \\
\text { Prairies/Subarctic }\end{array}$} & \multicolumn{2}{|c|}{$\begin{array}{c}\text { Boreal Plains, } \\
\text { Plains/Subarctic }\end{array}$} & \multicolumn{2}{|c|}{$\begin{array}{c}\text { Boreal } \\
\text { Shield/Subarctic }\end{array}$} & \multicolumn{2}{|c|}{$\begin{array}{c}\text { Taiga } \\
\text { Shield/Subarctic }\end{array}$} \\
\hline & & DDE (ng/g) & PCB (ng/g) & DDE (ng/g) & PCB (ng/g) & DDE (ng/g) & PCB (ng/g) & DDE (ng/g) & PCB (ng/g) \\
\hline Walleye/pickerel & $0.31(0.05)$ & 0 & 0 & 0 & 0 & 0 & 0 & 0 & 0 \\
\hline Northern pike & $0.27(0.09)$ & 0 & 0 & 0 & 0 & $0.89(0.15)$ & $0.34(0.12)$ & 0 & 0 \\
\hline Lake whitefish & $1.24(0.56)$ & $1.34(0)$ & $0.33(0)$ & $1.22(0.71)$ & $0.23(0.32)$ & $1.61(0.91)$ & $0.17(0.33)$ & $0.65(0.54)$ & $0.20(0.27)$ \\
\hline Lake trout & $0.84(0.14)$ & $11.73(5.76)$ & $9.24(2.58)$ & $11.73(5.76)$ & $9.24(2.58)$ & $15.8(2.87)$ & $7.41(1.29)$ & $7.65(2.13)$ & $11.06(2.98)$ \\
\hline
\end{tabular}

Note: EPA, eicosapentaenoic acid; DHA, docosahexaenoic acid; DDE, dichlorodiphenyldichloroethylene; PCB, polychlorinated biphenyls. $\mathrm{EPA}+\mathrm{DHA}$ in grams per $100 \mathrm{~g}$ of raw fish; ng/g, nanograms per $1 \mathrm{~g}$ of fish. Data reported are mean (SD). 0 indicates non-detectible concentration.

(ANOVA, $p=0.99$ for PCB, and $p=0.94$ for DDE) among the four ecozones. For n-3 FAs content, whitefish and lake trout had significantly higher concentrations of EPA + DHA (1.24 g/100 g and $0.84 \mathrm{~g} / 100 \mathrm{~g}$, respectively) compared with walleye $(0.31 \mathrm{~g} / 100 \mathrm{~g})$ and northern pike $(0.27 \mathrm{~g} / 100 \mathrm{~g}$ of fish).

In addition, we assessed dietary and lifestyle behavior in individuals with and without T2D to examine if participants diagnosed with T2D tend to change their diets. The first sensitivity analysis aimed to compare diet and lifestyle practice between participants recently diagnosed with T2D ( $0-5$ years) and those who have T2D for a long period of time ( $>5$ years) (Table S1). The analysis showed no statistically significant differences in physical activity, macronutrient intakes, and fish consumption between the two groups.

The second sensitivity analysis explored diet and lifestyle in participants with and without T2D, which may be associated with self-reported dieting status (Table S2). The analysis revealed that there were no differences in macronutrient intakes between individuals with and without T2D. However, dieting participants had higher mean BMI, reported a slightly lower smoking rate, and higher physical activity compared with non-dieting subjects. Fish and associated n-3 FA consumption was comparable between the two groups. 


\section{Discussion}

The prevalence of self-reported T2D in Manitoba FNs adults aged 19 years and older was 22\%, which is similar to the estimate reported by the Manitoba First Nation RHS (21\%) in individuals aged $\geq 18$ years (AMC 2012). These rates are more than three times higher than those in the general Canadian population (6.8\% in individuals aged $\geq 20$ years) (Pelletier et al. 2012). In this study, more men than women reported having T2D (26\% vs. $20 \%)$. The average amount of traditional food consumed by the participants of this study was $45 \mathrm{~g} /$ person per day, and $82 \%$ of participants reported eating fish (Chan et al. 2012).

In this cross-sectional study, a dose-response relationship between fish intake and self-reported T2D was found. Statistically significant inverse associations between the frequency of fish consumption and self-reported T2D were observed in the multivariable-adjusted models when compared with no fish intake or less that one portion per month. Fish intake of one portion per week and more may decrease the OR for T2D by $60 \%$. Similarly, the highest intake of n-3 FAs was associated with a $52 \%$ decrease in T2D prevalence compared with no n-3 FAs intake. The stronger protective effect of fish consumption on T2D prevalence than that of n-3 FAs intake might be attributed to other nutrients contained in fish such as protein and vitamin $\mathrm{D}$, which have been reported to decrease the risk of T2D by a favorable effect on glucose metabolism (Pittas et al. 2007). The protective effect of $n-3$ FAs was also found in the analyses stratified by age group ( $>45$ years vs. $\geq 45$ years), particularly in the models adjusted for DDE and PCB intakes.

Our findings are consistent with a number of previous population-based prospective cohort studies on the relationships between fish consumption and n-3 FAs intake on the one hand and T2D prevalence on the other, conducted among different populations (Patel et al. 2009; Nanri et al. 2011; Villegas et al. 2011). Patel et al. (2009) reported that consumption of one or more portion of fish per week decreased the OR for diabetes by about $25 \%$ compared with less than one portion per week in analyses adjusted for a number of risk factors for diabetes. Nanri et al. (2011) found that fish intake in men was significantly associated with a decreased risk of T2D with the OR values of T2D prevalence for the highest compared with the lowest quartile of intake being 0.73 (95\% CI: 0.54-1.00) for total fish intake and 0.68 (95\% CI: 0.5-0.92) for small and medium fish. Villegas et al. (2011) found that the relative risks for quintiles of fish intake were $1.00,0.96,0.84,0.8$, and $0.89(p=0.003)$. Recent meta-analyses of prospective studies found that in the overall analysis, fish consumption and dietary n-3 FAs intake were not associated with lower risk of T2D (Wallin et al. 2012; Wu et al. 2012; Zheng et al. 2012). However, geographical differences in the associations were demonstrated with a protective effect of fish and n-3 FAs consumption on T2D in Asian countries (Nanri et al. 2011; Villegas et al. 2011) and positive associations in the US population (Kaushik et al. 2009). This heterogeneity may originate from several sources including genetic differences or genediet interactions (Dedoussis et al. 2007; Lee et al. 2011). The heterogeneity may also originate from differences in the type and amount of fish consumed as well as the concentrations of contaminants in fish species that were not considered in previous studies (Lee and Jacobs 2010). In fact, Wallin et al. (2015) reported that dietary contaminants in fish may influence the relationship between fish consumption and T2D prevalence. Limited data on the association between fish consumption and T2D prevalence are available for the Indigenous population. A cross-sectional study in Canadian FNs communities reported that the consumption of whitefish and trout may have reduced the risk of diabetes, whereas exposure to contaminants (DDE, PCB) increased the risk of T2D (Philibert et al. 2009).

The positive associations between n-3 FAs intake and T2D prevalence could reflect beneficial effects on dyslipidemia characterized by low HDL-cholesterol and high triglyceride levels. There is evidence that n-3 FAs can decrease triglyceride levels and improve glucose tolerance and insulin sensitivity 
(Ebbesson et al. 2005), but have no effect on HDL-cholesterol levels (Hartweg et al. 2009). Tørris et al. $(2014,2017)$ reported that fish consumption was associated with a lower risk of metabolic syndrome. Experimental studies reported that fish or fish oil supplements may improve insulin secretion and insulin sensitivity (Akinkuolie et al. 2011).

Dietary DDE and PCB intake showed no association with T2D prevalence in the model controlling for several covariates; however, there were positive, but not statistically significant, associations in the models controlling for EPA + DHA intake in the total population and older individuals. Several previous studies have suggested a positive association between serum DDE and PCB concentrations and T2D prevalence (Codru et al. 2007; Philibert et al. 2009; Turyk et al. 2009). Statistically significant positive associations between dietary DDE and PCB intake and T2D prevalence were confirmed in Ontario FNs where dietary POP exposure was higher than in Manitoba FNs (Marushka et al. 2017). In the current study, the weak association between exposure to DDE and PCB and T2D prevalence may be explained by very low dietary DDE and PCB intake via fish; however, it was slightly higher among older participants than younger ones as they consumed higher amounts of fish.

The percentage of participants consuming fish differed across Manitoba regions depending on variety and availability of fish species. For example, $90 \%-94 \%$ of participants reported eating fish at least once in the prior year in the Boreal Plains, Plains/Subarctic, and Taiga Shield/Subarctic ecozones, in contrast with $80 \%$ of responders from the Boreal Shield/Subarctic ecozone and only $68 \%$ of participants living in the Prairies/Plains and Prairies/Subarctic ecozones. Even though most of the participants reported eating fish in the prior year, the daily mean intake of fish was estimated to be relatively low except in the Taiga Shield/Subarctic region. Walleye, northern pike, lake whitefish, and lake trout were the most consumed species among 30 types of fish, constituting almost $80 \%$ of the total fish intake.

Regional differences in the prevalence of T2D were found across four Manitoba ecozones, with the lowest observed T2D rate in the Taiga Shield/Subarctic region (5\%). Dietary characteristics and lifestyle practice were analyzed and compared among individuals living in the four Manitoba regions. No statistically significant differences in dietary intake were observed; however, participants living in the Taiga Shield/Subarctic region consumed much more fish than those from the other regions $(25.6 \mathrm{~g} / \mathrm{d}$ vs. $11.4 \mathrm{~g} / \mathrm{d}, 5.8 \mathrm{~g} / \mathrm{d}, 5.9 \mathrm{~g} / \mathrm{d})$. In addition, they reported a higher consumption of whitefish and lake trout, which contain high levels of n-3 FAs.

The DDE and PCB concentrations varied among the four most consumed fish species. DDE and PCB were not detectable in walleye and northern pike, whereas lake trout had the highest concentrations. Elevated concentrations of POP in lake trout were also documented in other studies (McGoldrick and Murphy 2015). The concentrations of DDE and PCB in fish species were comparable across four Manitoba ecozones.

This study has several limitations. As the design of our study is cross-sectional, we cannot state the causal relationship between fish and n-3 FAs consumption and T2D prevalence. Second, the reliance on self-reporting for the calculation of the prevalence of T2D could have resulted in an underestimation. We validated our estimates of T2D prevalence by comparing them with the self-reports presented by the RHS, which is a representative study for FNs living on reserves conducted over the same period of time (2008-2010) as our data collection. The RHS collected more comprehensive information on T2D prevalence that included data on the type of treatment people used to control their diabetes, how frequently people checked their blood sugar levels, complications of diabetes experienced, whether individuals adopted a healthier lifestyle including diet and exercise, attendance of a diabetes clinic, and getting diabetes education. A study among Cree FNs living in northern Quebec reported that $4.5 \%$ of participants had undiagnosed diabetes 
based on glucose levels that indicates diabetes $(\geq 7 \mathrm{mmol} / \mathrm{L})$, but no mention of diabetes in their medical charts (Bobet 2013). Third, self-reported dietary intake estimates may lead to some degree of measurement error of the intake level. Some previous studies reported that overweight and obese individuals tend to underestimate their energy, fat, and carbohydrate intake (Heitmann and Lissner 1995), whereas other scientists reported that both obese and non-obese subjects tend to underreport between-meal snack foods (Poppitt et al. 1998). Bailey et al. (2007) reported that weight status, education, and smoking status are characteristics consistently associated with underreporting. The authors suggested that these factors should be used to control for errors in statistical models when examining relationships with diet and health (Bailey et al. 2007). In the current study, the results were controlled for lifestyle confounders including total energy intake, body mass index, physical activity, smoking, education level, and crowding. Other potential covariates such as dietary fat, saturated fat, carbohydrate, fruit, and vegetable intake were also considered. However, because they did not change the estimates of the association between T2D prevalence and fish consumption, they were not included in the models. Further, lifestyle and dietary habits associated with both fish consumption and T2D prevalence may influence the results. To examine differences in dietary and lifestyle behavior between diabetic and non-diabetic individuals, several sensitivity analyses were performed. The analyses revealed that no statistical differences in habits as well as fish consumption, dietary n-3 FAs, and POP intake were found (Supplemental Material 1). Finally, physical activity level was selfreported and therefore may not be entirely accurate. Finally, we estimated PCB and DDE exposure from fish consumption and so the total $\mathrm{PCB}$ and DDE intake may be even higher. Future studies may need to verify this using biomonitoring data. To our knowledge, this is the first study investigating the relationships between fish consumption, dietary intake of n-3 FAs and POP, and T2D prevalence in Manitoba FNs living on reserves. The strength of our study is a large sample size, which is representative of all FNs adults living on reserves in Manitoba. POP concentrations in locally harvested fish were measured in this study. The individual total dietary PCB and DDE intake was calculated based on community-specific data of POP content in fish species. Also, we were able to control our results for a number of risk factors for T2D such as age, gender, BMI, smoking, physical activity, energy intake, and education level. Several epidemiological studies reported a positive association between n-3 FAs serum levels and T2D prevalence (Virtanen et al. 2014). We observed the same positive relationship between dietary $\mathrm{n}-3$ FAs intake and T2D prevalence which is useful in developing a dietary advisory for fish consumption.

\section{Conclusion}

The prevalence of self-reported T2D in Manitoba FNs was 22\%. Negative dose-response relationships between fish consumption and associated long-chain n-3 FAs intake and T2D prevalence were found. Fish consumption of 2-3 portions per month and consumption of one portion per week and more reduced the odds of T2D prevalence by about $50 \%$ and $60 \%$, respectively, compared with no fish consumption or less than one portion per month. Similarly, the intake of long-chain n-3 FAs was inversely associated with self-reported T2D. Dietary DDE and PCB intake was not associated with T2D prevalence. The most consumed fish species in the four Manitoba ecozones were walleye, northern pike, lake whitefish, and lake trout, constituting $78 \%$ of the total fish consumption. The concentrations of DDE and PCB in fish samples were low or not-detectible. Thus, the exposure to POP from fish was negligible in Manitoba FNs communities. Lake whitefish and lake trout were the main sources of long-chain n-3 FAs, whereas lake trout was the primary contributor to the total DDE and PCB intake. These findings suggest that consumption of traditionally harvested fish may have a beneficial effect on T2D prevalence in Manitoba FNs. However, causal relationships between fish consumption and associated n-3 FAs intake and T2D prevalence need to be investigated in a 
prospective study. The results of this study will be useful in developing fish consumption advisories and prevention programs to slow the increase in T2D prevalence in Manitoba FNs. This study serves as a case study for other regions in Canada and the rest of the world for developing fish consumption advisories. It is important to measure POP concentrations and n-3 FAs in locally harvested fish for future studies.

\section{Acknowledgements}

We would like to express our gratitude to all participants for their cooperation and participation in the First Nations Food, Nutrition and Environment Study (FNFNES). We thank all First Nations community members who collected food and water samples, assisted in data collection, coordinated research activities, and arranged meetings and public gathering to share information. FNFNES is funded by Health Canada and the communication of the results to the communities was also funded by the Canadian Institute of Health Research. H.M. Chan is supported by the Canada Research Chair Program.

\section{Author contributions}

LM, MB, DS, HS, CT, and HMC conceived and designed the study. LM, MB, DS, HS, KF, AB, CT, and HMC performed the experiments/collected the data. LM, MB, DS, HS, AI, KF, AB, CT, and HMC analyzed and interpreted the data. $\mathrm{LM}, \mathrm{MB}, \mathrm{DS}, \mathrm{HS}, \mathrm{AI}, \mathrm{KF}, \mathrm{AB}, \mathrm{CT}$, and $\mathrm{HMC}$ contributed resources. $\mathrm{LM}, \mathrm{MB}, \mathrm{DS}, \mathrm{HS}, \mathrm{AI}, \mathrm{KF}, \mathrm{AB}, \mathrm{CT}$, and HMC drafted or revised the manuscript.

\section{Competing interests}

The authors have declared that no competing interests exist.

\section{Data accessibility statement}

All relevant data are within the paper and in the Supplementary Material.

\section{Supplementary material}

The following Supplementary Material is available with the article through the journal website at doi:10.1139/facets-2017-0023.

Supplementary Material 1

\section{References}

Akinkuolie AO, Ngwa JS, Meigs JB, and Djoussé L. 2011. Omega-3 polyunsaturated fatty acid and insulin sensitivity: a meta-analysis of randomized controlled trials. Clinical Nutrition, 30(6): 702-707. PMID: 21959352 DOI: 10.1016/j.clnu.2011.08.013

Assembly of Manitoba Chiefs (AMC). 2012. First Nations Regional Health Survey (RHS) phase 2 (2008-2010): Manitoba regional report. Assembly of Manitoba Chiefs, Winnipeg, Manitoba (Revised November 2012).

Bailey RL, Mitchell DC, Miller C, and Smiciklas-Wright H. 2007. Assessing the effect of underreporting energy intake on dietary patterns and weight status. Journal of the American Dietetic Association, 107(1): 64-71. PMID: 17197273 DOI: 10.1016/j.jada.2006.10.009

Bobet E. 2013. Summary report on the Nituuchischaayihtitaau Aschii multi-community environmentand-health study. Public health report Series 4 on the health of the population. Cree Board of Health 
and Social Services of James Bay, Chisasibi, Quebec [online]: Available from bape.gouv.qc.ca/sections/ mandats/uranium-enjeux/documents/PREMNAT11.pdf.

Canadian Diabetes Association. 2015. 2015 Report on diabetes-driving change, pp. 1-84 [online]: Available from diabetes.ca/getmedia/5a7070f0-77ad-41ad-9e95-ec1bc56ebf85/2015-report-ondiabetes-driving-change-english.pdf.aspx $\% 5 \mathrm{Cn}$.

Chan L, Receveur O, Sharp D, Schwartz H, Ing A, Fediuk K, et al. 2012. First Nations Food, Nutrition and Environment Study (FNFNES): results from Manitoba (2010). University of Northern British Columbia, Prince George, British Columbia [online]: Available from fnfnes.ca/docs/ FNFNES_Ontario_Regional_Report_2014_final.pdf.

Codru N, Schymura MJ, Negoita S, Rej R, and Carpenter DO. 2007. Diabetes in relation to serum levels of polychlorinated biphenyls and chlorinated pesticides in adult native Americans. Environmental Health Perspectives, 115(10): 1442-1447. PMID: 17938733 DOI: 10.1289/ ehp. 10315

Dannenbaum D, Kuzmina E, Lejeune P, Torrie J, and Gangbe M. 2008. Prevalence of diabetes and diabetes-related complications in First Nations communities in Northern Quebec (Eeyou Istchee), Canada. Canadian Journal of Diabetes, 32(1): 46-52. DOI: 10.1016/S1499-2671(08) $21010-5$

Dedoussis GVZ, Kaliora AC, and Panagiotakos DB. 2007. Genes, diet and type 2 diabetes mellitus: a review. The Review of Diabetic Studies, 4(1): 13-24. PMID: 17565412

Deering KN, Lix LM, Bruce S, and Young TK. 2009. Chronic diseases and risk factors in Canada's northern populations: longitudinal and geographic comparisons. Canadian Journal of Public Health, 100(1): 14-17. PMID: 19263969

Dewailly E, Blanchet C, Lemieux S, Sauvé L, Gingras S, Ayotte P, et al. 2001. n-3 Fatty acids and cardiovascular disease risk factors among the Inuit of Nunavik. The American Journal of Clinical Nutrition, 74(4): 464-473. PMID: 11566644

Djoussé L, Gaziano JM, Buring JE, and Lee I-M. 2011. Dietary omega-3 fatty acids and fish consumption and risk of type 2 diabetes. The American Journal of Clinical Nutrition, 93(1): 143-150. DOI: 10.3945/ajcn.110.005603

Donaldson SG, Van Oostdam J, Tikhonov C, Feeley M, Armstrong B, Ayotte P, et al. 2010. Environmental contaminants and human health in the Canadian Arctic. Science of the Total Environment, 408(22): 5165-5234. PMID: 20728918 DOI: 10.1016/j.scitotenv.2010.04.059

Ebbesson SOE, Risica PM, Ebbesson LOEEA, Kennish JM, and Tejero ME. 2005. Omega-3 fatty acids improve glucose tolerance and components of the metabolic syndrome in Alaskan Eskimos: the Alaska Siberia project. International Journal of Circumpolar Health, 64(4): 396-408. PMID: 16277123 DOI: 10.3402/ijch.v64i4.18016

Fedor D, and Kelley DS. 2009. Prevention of insulin resistance by $\mathrm{n}-3$ polyunsaturated fatty acids. Current Opinion in Clinical Nutrition and Metabolic Care, 12(2): 138-146. PMID: 19202385 DOI: 10.1097/MCO.0b013e3283218299

First Nations Information Governance Centre (FNIGC). 2012. First Nations Regional Health Survey (RHS) 2008/10: National report on adults, youth and children living in First Nations communities. FNIGC, Ottawa, Ontario [online]: Available from fnigc.ca. 
Guariguata L, Whiting DR, Hambleton I, Beagley J, Linnenkamp U, and Shaw JE. 2014. Global estimates of diabetes prevalence for 2013 and projections for 2035. Diabetes Research and Clinical Practice, 103(2): 137-149. PMID: 24630390 DOI: 10.1016/j.diabres.2013.11.002

Hartweg J, Farmer AJ, Holman RR, and Neil A. 2009. Potential impact of omega-3 treatment on cardiovascular disease in type 2 diabetes. Current Opinion in Lipidology, 20(1): 30-38. PMID: 19133409 DOI: 10.1097/MOL.0b013e328321b3be

Health Canada. 2007. Eating well with Canada's food guide - First Nations, Inuit and Métis. Health Canada, Ottawa, Ontario [online]: Available from canada.ca/en/health-canada/services/ food-nutrition/reports-publications/eating-well-canada-food-guide-first-nations-inuit-metis.html.

Health Canada. 2015. Canadian nutrient file (CNF) (online database). Health Canada, Ottawa, Ontario [online]: Available from webprod3.hc-sc.gc.ca/cnf-fce/index-eng.jsp.

Heitmann BL. and Lissner L. 1995. Dietary underreporting by obese individuals-is it specific or non-specific? BMJ, 311(7011): 986-989. PMID: 7580640

Huerta JM, Tormo MJ, Egea-Caparrós JM, Ortolá-Devesa JB, and Navarro C. 2009. Accuracy of self-reported diabetes, hypertension and hyperlipidemia in the adult Spanish population. DINO study findings. Revista Espanola de Cardiologia, 62(2): 143-152. DOI: 10.1016/S1885-5857(09) $71532-4$

Ibrahim MM, Fjære E, Lock E-J, Naville D, Amlund H, Meugnier E, et al. 2011. Chronic consumption of farmed salmon containing persistent organic pollutants causes insulin resistance and obesity in mice. PLoS ONE, 6(9): e25170. PMID: 21966444 DOI: 10.1371/journal.pone.0025170

Jamieson JA, Weiler HA, Kuhnlein HV and Egeland GM. 2012. Traditional food intake is correlated with iron stores in Canadian Inuit Men. The Journal of Nutrition, 142(4): 764-770. PMID: 22378332 DOI: $10.3945 / j n .111 .140475$

Kaushik M, Mozaffarian D, Spiegelman D, Manson JE, Willett WC, and Hu FB. 2009. Long-chain omega-3 fatty acids, fish intake, and the risk of type 2 diabetes mellitus. The American Journal of Clinical Nutrition, 90(3): 613-620. PMID: 19625683 DOI: 10.3945/ajcn.2008.27424

Kuhnlein HV, and Receveur O. 2007. Local cultural animal food contributes high levels of nutrients for Arctic Canadian Indigenous adults and children. The Journal of Nutrition, 137(4): 1110-1114. PMID: 17374689

Kuhnlein HV, Receveur O, Soueida R, and Egeland GM. 2004. Arctic indigenous peoples experience the nutrition transition with changing dietary patterns and obesity. Journal of Nutrition, 134(6): 1447-1453. PMID: 15173410

Lee D-H, and Jacobs DR Jr. 2010. Inconsistent epidemiological findings on fish consumption may be indirect evidence of harmful contaminants in fish. Journal of Epidemiology and Community Health, 64(3): 190-192. PMID: 20203120 DOI: 10.1136/jech.2009.093328

Lee D-H, Lee I-K, Song K, Steffes M, Toscano W, Baker BA, et al. 2006. A strong dose-response relation between serum concentrations of persistent organic pollutants and diabetes: results from the National Health and Examination Survey 1999-2002. Diabetes Care, 29(7): 1638-1644. PMID: 16801591 DOI: 10.2337/dc06-0543 
Lee Y-C, Lai C-Q, Ordovas JM, and Parnell LD. 2011. A database of gene-environment interactions pertaining to blood lipid traits, cardiovascular disease, and type 2 diabetes. Journal of Data Mining in Genomics \& Proteomics, 2(1): 1-8. DOI: 10.4172/2153-0602.1000106

Lix LM, Bruce S, Sarkar J, and Young TK. 2009. Risk factors and chronic conditions among Aboriginal and non-Aboriginal populations. Health Reports, 20(4): 21-29. PMID: 20108603

Maletta H, and Aires B. 2007. Weighting. SPSS tools, pp. 1-19 [online]: Available from spsstools.net.

Marushka L, Batal M, David W, Schwartz H, Ing A, Fediuk K, et al. 2017. Association between fish consumption, dietary omega- 3 fatty acids and persistent organic pollutants intake, and type 2 diabetes in 18 First Nations in Ontario, Canada. Environmental Research, 156: 725-737. PMID: 28482294 DOI: $10.1016 /$ j.envres.2017.04.034

McGoldrick DJ, and Murphy EW. 2015. Concentration and distribution of contaminants in lake trout and walleye from the Laurentian Great Lakes (2008-2012). Environmental Pollution, 217: 85-96. PMID: 26740246 DOI: 10.1016/j.envpol.2015.12.019

Millar WJ, and Young TK. 2003. Tracking diabetes: prevalence, incidence and risk factors. Health Reports, 14(3): 35-47. PMID: 12816014

Muley A, Muley P, and Shah M. 2014. ALA, fatty fish or marine n-3 fatty acids for preventing DM?: a systematic review and meta-analysis. Current Diabetes Reviews, 10(3): 158-165. PMID: 24828061 DOI: $10.2174 / 1573399810666140515113137$

Nanri A, Mizoue T, Noda M, Takahashi Y, Matsushita Y, and Poudel-Tandukar K. 2011. Fish intake and type 2 diabetes in Japanese men and women: the Japan Public Health Center-based Prospective Study. The American Journal of Clinical Nutrition, 94(8): 884-891. DOI: 10.3945/ ajcn.111.012252

Naqshbandi M, Harris SB, Esler JG, and Antwi-Nsiah F. 2008. Global complication rates of type 2 diabetes in Indigenous peoples: a comprehensive review. Diabetes Research and Clinical Practice, 82(1): 1-17. PMID: 18768236 DOI: 10.1016/j.diabres.2008.07.017

Nkondjock A, and Receveur O. 2003. Fish-seafood consumption, obesity, and risk of type 2 diabetes: an ecological study. Diabetes \& Metabolism, 29(6): 635-642. PMID: 14707894 DOI: $10.1016 /$ S1262-3636(07)70080-0

Patel PS, Sharp SJ, Luben RN, Khaw K-T, Bingham SA, Wareham NJ, et al. 2009. Association between type of dietary fish and seafood intake and the risk of incident type 2 diabetes: the European prospective investigation of cancer (EPIC)-Norfolk cohort study. Diabetes Care, 32(10): 1857-1863. PMID: 19592633 DOI: 10.2337/dc09-0116

Pelletier C, Dai S, Roberts KC, Bienek A, Onysko J, and Pelletier L. 2012. Report summary. Diabetes in Canada: facts and figures from a public health perspective. Chronic Diseases and Injuries in Canada, 33(1):53-54. PMID: 23294922

Philibert A, Schwartz H, and Mergler D. 2009. An exploratory study of diabetes in a First Nation community with respect to serum concentrations of $p, p^{\prime}-\mathrm{DDE}$ and PCBs and fish consumption. International Journal of Environmental Research and Public Health, 6(12): 3179-3189. PMID: 20049255 DOI: 10.3390/ijerph6123179 
Pittas AG, Lau J, Hu FB, and Dawson-Hughes B. 2007. The role of vitamin D and calcium in type 2 diabetes. A systematic review and meta-analysis. The Journal of Clinical Endocrinology \& Metabolism, 92(6): 2017-2029. PMID: 17389701 DOI: 10.1210/jc.2007-0298

Poppitt SD, Swann D, Black AE, and Prentice AM. 1998. Assessment of selective under-reporting of food intake by both obese and non-obese women in a metabolic facility. International Journal of Obesity, 22(4): 303-311. PMID: 9578234 DOI: 10.1038/sj.ijo.0800584

Proust F, Lucas M, and Dewailly E. 2014. Fatty acid profiles among the Inuit of Nunavik: current status and temporal change. Prostaglandins, Leukotrienes and Essential Fatty Acids (PLEFA), 90(5): 159-167. PMID: 24582818 DOI: 10.1016/j.plefa.2014.02.001

Raper N, Perloff B, Ingwersen L, Steinfeldt L, and Anand J. 2004. An overview of USDA's dietary intake data system. Journal of Food Composition and Analysis, 17(3-4): 545-555. DOI: 10.1016/j. jfca.2004.02.013

Schneider ALC, Pankow JS, Heiss G, and Selvin E. 2012. Validity and reliability of self-reported diabetes in the atherosclerosis risk in communities study. American Journal of Epidemiology, 176(8): 738-743. PMID: 23013620 DOI: 10.1093/aje/kws156

Seabert TA, Pal S, Pinet BM, Haman F, Robidoux MA, Imbeault P, et al. 2014. Elevated contaminants contrasted with potential benefits of $\omega$-3 fatty acids in wild food consumers of two remote First Nations communities in Northern Ontario, Canada. PLoS ONE, 9(3): e90351. PMID: 24598815 DOI: 10.1371/journal.pone.0090351

Sobek A, McLachlan MS, Borgå K, Asplund L, Lundstedt-Enkel K, Polder A, et al. 2010. A comparison of PCB bioaccumulation factors between an arctic and a temperate marine food web. Science of the Total Environment, 408(13): 2753-2760. PMID: 20385405 DOI: 10.1016/j.scitotenv.2010.03.013

Tørris C, Molin M, and Småstuen MC. 2014. Fish consumption and its possible preventive role on the development and prevalence of metabolic syndrome-a systematic review. Diabetology \& Metabolic Syndrome, 6(1): 112. PMID: 25352919 DOI: 10.1186/1758-5996-6-112

Tørris C, Molin M, and Småstuen MC. 2017. Lean fish consumption is associated with beneficial changes in the metabolic syndrome components: a 13-year follow-up study from the Norwegian Tromsø study. Nutrients, 9(3):247. PMID: 28282859 DOI: 10.3390/nu9030247

Turyk M, Anderson H, Knobeloch L, Imm P, and Persky V. 2009. Organochlorine exposure and incidence of diabetes in a cohort of great lakes sport fish consumers. Environmental Health Perspectives, 117(7): 1076-1082. PMID: 19654916 DOI: 10.1289/ehp.0800281

van Woudenbergh GJ, van Ballegooijen AJ, Kuijsten A, Sijbrands EJG, van Rooij FJA, Geleijnse JM, et al. 2009. Eating fish and risk of type 2 diabetes. A population-based, prospective follow-up study. Diabetes Care, 32(11): 2021-2026. PMID: 19675200 DOI: 10.2337/dc09-1042

Villegas R, Xiang Y-B, Elasy T, Li H-L, Yang G, Cai H, et al. 2011. Fish, shellfish, and long-chain n-3 fatty acid consumption and risk of incident type 2 diabetes in middle-aged Chinese men and women. The American Journal of Clinical Nutrition, 94(2): 543-551. DOI: 10.3945/ajcn.111.013193

Virtanen JK, Mursu J, Voutilainen S, Uusitupa M, and Tuomainen T-P. 2014. Serum omega-3 polyunsaturated fatty acids and risk of incident type 2 diabetes in men: the Kuopio Ischemic Heart Disease Risk Factor Study. Diabetes Care, 37(1): 189-196. PMID: 24026545 DOI: 10.2337/dc13-1504 
Wallin A, Di Giuseppe D, Orsini N, Patel PS, Forouhi NG, and Wolk A. 2012. Fish consumption, dietary long-chain n-3 fatty acids, and risk of type 2 diabetes: systematic review and meta-analysis of prospective studies. Diabetes Care, 35(4): 918-929. PMID: 22442397 DOI: 10.2337/dc11-1631

Wallin A, Di Giuseppe D, Orsini N, Åkesson A, Forouhi NG, and Wolk A. 2015. Fish consumption and frying of fish in relation to type 2 diabetes incidence: a prospective cohort study of Swedish men. European Journal of Nutrition, 56(2):843-852. PMID: 26687687 DOI: 10.1007/s00394015-1132-6

Wu JHY, Micha R, Imamura F, Pan A, Biggs ML, Ajaz O, et al. 2012. Omega-3 fatty acids and incident type 2 diabetes: a systematic review and meta-analysis. British Journal of Nutrition, 107(Suppl. 2): S214-S227. PMID: 22591895 DOI: 10.1017/S0007114512001602

Young TK, Reading J, Elias B, and O’Neil JD. 2000. Type 2 diabetes mellitus in Canada's First Nations: status of an epidemic in progress. CMAJ, 163(5): 561-566. PMID: 11006768

Zheng J-S, Huang T, Yang J, Fu Y-Q, and Li D. 2012. Marine n-3 polyunsaturated fatty acids are inversely associated with risk of type 2 diabetes in Asians: a systematic review and meta-analysis. PLoS ONE, 7(9): e44525. PMID: 22984522 DOI: 10.1371/journal.pone.0044525 